\title{
Visiones críticas en torno a los deportes a fines del siglo XIX*
}

\section{Critical views about sports in the late Nineteenth Century}

Recibido: 22 de abril de 2014 - Revisado: 27 de agosto de 2014 - Aceptado: 06 de noviembre de 2014

\author{
Gabriel Angelotti Pasteur**
}

\section{Resumen}

El presente artículo expone y analiza las críticas de intelectuales del siglo XIX hacia los deportes. Desde campos diferentes del saber (filosofía evolucionista, antropología y economía), Herbert Spencer (1860/1904), Edward Tylor (1881/1973) y Thorstein Veblen (1899/2005) coincidieron en cuestionar la primacía de los deportes sobre las prácticas tradicionales, rituales y folclóricas. Estos autores, sin llegar a los extremos de los ludistas respecto de las máquinas industriales, exaltaron los aspectos desfavorables de los ejercicios físicos, sembrando una semilla de duda que perdura hasta nuestros días. La importancia de conocer tales argumentos radica en la manera en que estos enfrentaron el fenómeno deportivo cuando comenzaba a institucionalizarse en un conjunto novedoso de ejercicios corporales, transformador y, al parecer, generador de bienestar físico y salud.

\section{Palabras clave}

Historia del deporte, deporte escolar, juegos y deportes, salud.

\section{Abstract}

This paper presents and analyzes the criticisms made by intellectuals of the nineteenth century towards sports. From different fields of knowledge (evolutionary philosophy, anthropology and economics) Herbert Spencer (1860/1904), Edward Tylor (1881/1973) and Thorstein Veblen (1899/2005) agreed to question the primacy of sports over traditional practices, rituals and folk. These authors, without reaching the ends of the luddites respect of industrial machines, extolled the unfavorable aspects of physical exercises, planting a seed of doubt that continues to this day. The importance of knowing these arguments lies in the way they faced the sporting phenomenon when it began to be institutionalized in a new set of corporal, transformative exercises and apparently a generator of fitness and health.

\section{Keywords}

History of sports, school sports, games and sports, health.

\footnotetext{
"Artículo de revisión que se apoya en la bibliografía presentada en la tesis "Fútbol e identidad. La formación histórica del deporte y la construcción de identidades colectivas en torno al fútbol en México" (realizada en el 2008 y mediante la cual el autor obtuvo el grado de doctor en Antropología Social por el Colegio de Michoacán, México) para analizar ciertos aspectos críticos de las prácticas deportivas de la actualidad.

** Profesor e investigador de la Facultad de Ciencias Antropológicas, Universidad Autónoma de Yucatán, México. Doctor en Antropología Social por el Colegio de Michoacán, México.

Correo electrónico: gabrielotti@uady.mx
} 
Casi todos los autores que han estudiado con deleite los eventos deportivos fueron realmente atrapados en una especie de deporte sagrado, de ritos y hazañas. No les importó

la violencia, el dopaje, la corrupción, la mercantilización desenfrenada, siempre que proteja la zozobra de los sentidos, la intoxicación, el éxtasis, el fervor y la obnubilación de que "hemos ganado". Brohm (2006)

El atleta... es la geisha de pie comprimido y atrofiado, destinado a convertirse en el instrumento de los demás.

Ecco (citado por Brohm, 2006)

\section{Introducción}

En nuestros días se repite con frecuencia que los deportes y, por extensión, todas las actividades atléticas, constituyen ocupaciones saludables que favorecen el bienestar físico y psíquico de las personas. Esta idea se ha transmitido como un axioma y no deja lugar a dudas, reflexiones ni a críticas. Para algunos autores esta característica entre salud y deporte es antigua, y sostienen que su origen puede rastrearse tanto en los denominados "pueblos primitivos" como en la cuna de la civilización occidental, Grecia. Sin embargo, la historiografía demuestra que los deportes nacieron a mediados del siglo XIX cuando algunos ejercicios físicos (con reminiscencia de antiguas prácticas rituales) se establecieron como prácticas formales, normalizadas e institucionalizadas (sports). Este hecho social ocurrió en el marco de un proceso que se relacionó con las transformaciones provocadas por la expansión del capitalismo mundial y la formación de los Estados nacionales (Brohm, 1976, 1982; Dunning \& Elias, 1986; Fábregas, 2001; García Ferrando, 1990; Guttman, 2004; Oliven \& Damo, 2001; Lüschen \& Weis, 1979; Thomas, Haumont \& Levet, 1988; entre otros). Desde entonces, los deportes se identificaron por las siguientes particularidades: secularismo, igualdad, especialización, racionalización, organización burocrática, cuantificación y la búsqueda del récord (Guttman, 2004).
Desde el pasado se emplearon citas, refranes populares, adagios y aforismos para exaltar el nexo entre los deportes y la salud. La más difundida de estas ideas fue aquella que inmortalizó Juvenal en las Sátiras ${ }^{1}$ y que dice: orandum est ut sit mens sana in corpore sano (Cabrera, 2004). La cual, posteriormente, como muchos otros juicios de Juvenal, fue sometida a la manipulación literaria e inmortalizada como una verdad que no requería comprobación mediante la fórmula sintética de "mente sana en cuerpo sano". John Locke (1986), quien es uno de los máximos exponentes del empirismo inglés del siglo XVII apoyó esa interpretación. Para Locke la educación física constituía una herramienta esencial en el proceso de formación de los jóvenes, ya que sin ella, los logros mentales alcanzados durante la instrucción serían inútiles (Mayer, 1984). Desde esta perspectiva, el ejercicio físico fue un complemento idóneo para el espíritu, el cual tendría como fin conservar la salud integral de los sujetos en su aspecto moral, intelectual y físico (Gallo, 2006).

Durante los siglos XVII, XVIII y XIX numerosos pedagogos incluyeron la enseñanza y la práctica de los ejercicios físicos en los programas educativos de nivel inicial. Mediante su incorporación Johann Heinrich Pestalozzi (1746-1827) buscó desarrollar el "hombre completo" (cuerpo, corazón y razón) (Sassano, 2003). Por su parte, John Dewey (1859-1952), autor que generó una significativa influencia en México y otros países de América Latina, aconsejaba la actividad física como un mecanismo para transmitir entre los educandos hábitos sociales y aquellos valores excelsos de la cultura occidental. Para llegar a esta meta, Dewey propuso la formación de centros de nutrición, defensa, vida comunal y correlación mental (Skirius, 1984). Otros pedagogos emplearían distintas metodologías para expandir esa "nueva ideología" deportiva por el orbe. Algunos, por ejemplo, realizaron torneos de exhibición y justas deportivas en pequeñas ciudades europeas. 
La diplomacia ocupó un papel preponderante en ese proceso de difusión y fue Pierre Fredy barón de Coubertin (1863-1937) el mayor exponente de la promoción del olimpismo en el mundo y de los beneficios de los nuevos ejercicios. A través de una tarea "de convencimiento" consiguió restaurar los Juegos Olímpicos de la Edad Moderna y promover una nueva filosofía: el "olimpismo", un movimiento internacional que, según el barón de Coubertin, permitiría alcanzar la tan ansiada paz mundial (Betancour \& Almeida, 2001). Coubertin creyó que los deportes podrían oficiar como uno de los instrumentos educativos más importantes para transformar la conducta humana y la sociedad. Esta ideología (el olimpismo) también contagió a Hippolyte Taine (1872), filósofo francés y uno de los principales exponentes de la corriente del naturalismo y de la labor educativa del doctor Thomas Arnold (1795-1842), quien había cambiado el sistema de enseñanza en la Escuela de Eton y que serviría de modelo en muchas de las public school de Gran Bretaña. La "anglomanía” y el entusiasmo acrítico por la modernidad deportiva, sin embargo, impidieron a Pierre de Coubertin observar ciertos aspectos negativos del sistema educativo inglés común por aquellos tiempos: como los castigos corporales sufridos por los estudiantes en manos de sus preceptores o el servilismo imperante de los alumnos pobres hacia los ricos en las universidades (Betancour \& Almeida, 2001).

Los primeros Juegos Olímpicos se realizaron en Atenas en el año de 1896 y desde allí, hasta nuestros días, cada cuatro años el evento se celebra en un país diferente, facilitando -en el sentido que propone Norbert Elias (1986)- el proceso de deportivización mundial. No obstante, debieron transcurrir varios años para que los juegos, las actividades lúdicas y el ocio lograsen consolidarse como temas de interés específico para los científicos sociales y un campo de estudio legítimo para estas disciplinas. Para fines del siglo XIX los ejercicios físicos comenzaron a cobrar relevancia entre ciertos sectores sociales, en particular, entre las élites locales y las burguesías urbanas.
En gran parte de Europa, Estados Unidos y Latinoamérica, los deportes fueron vistos como sinónimos de modernidad, progreso y salud. La apertura de instituciones deportivas y clubes, la construcción de estadios, la realización de competencias locales y regionales y, en especial, de torneos internacionales, aceleraron el "proceso de deportivización mundial". La inclusión de las prácticas deportivas en los programas educativos selló la importancia de esos ejercicios en la formación y el desarrollo físico y moral de las personas. Este conjunto de transformaciones debemos considerarlo a la luz de la expansión del capitalismo mundial, la formación de los Estados nacionales y el interés en generar cambios en la naturaleza y en la conducta de los sujetos. Desde entonces, la suposición del paralelismo entre deportes y bienestar físico y espiritual en los individuos se aceptó como un patrón o modelo de conducta normal y una meta a seguir.
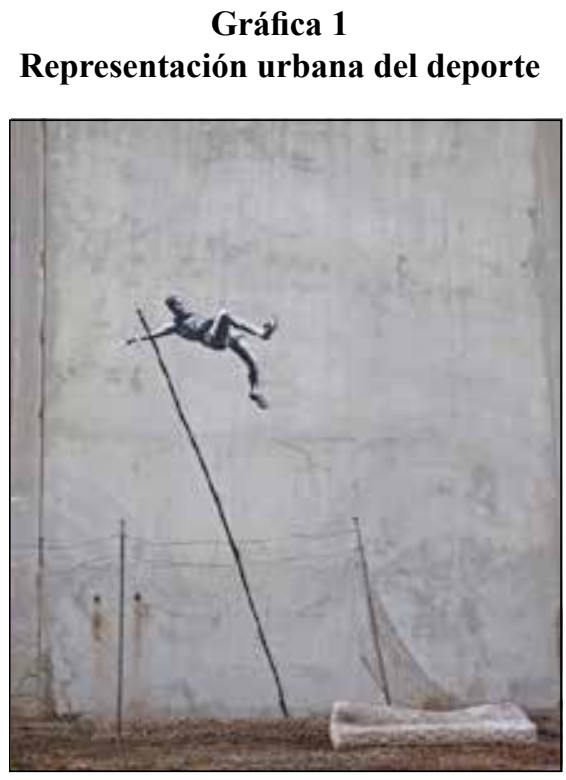

Fuente: Banksy (2012, citado por Horlock, 24 de julio de 2012) $)^{2}$.

En la actualidad las relaciones mencionadas entre los conceptos de bienestar físico y deportes siguen vigentes, y tan profunda es la raíz de estas ideas que pocos osarían cuestionarlas, so pena de verse sometidos a la crítica 
implacable, feroz o, en su grado más extremo, a la descalificación. Empero, hechos que ocurren en el presente permiten dudar respecto de ese "aparente" binomio indisoluble entre el deporte y el bienestar de las personas y la sociedad.

A modo de ejemplo, referimos los siguientes problemas que afectan el campo deportivo, la vida de los deportistas y el entorno social donde las actividades físicas se desarrollan:

a) La muerte prematura de deportistas (denominada "muerte súbita"), en muchos casos producida por cardiopatías, tumores y otras patologías desconocidas ${ }^{4}$.

b) El uso de sustancias químicas para aumentar el rendimiento físico de los deportistas durante las competencias (tan común en el atletismo, natación, ciclismo y fútbol).

c) La transformación (o desfiguración) corporal producto de la repetición localizada de ciertos movimientos y la propensión a contraer enfermedades: tal como ocurre en el levantamiento de pesas, gimnasia olímpica y el boxeo ${ }^{5}$.

d) En el aspecto social, destacamos aquellas alteraciones provocadas, entre otros protagonistas, por fanáticos violentos (hooligans, tifosi y barras bravas), quienes participan de este campo como simpatizantes o espectadores y utilizan los espacios deportivos para manifestar sentimientos de odio hacia rivales, exaltar nacionalismos, actitudes xenofóbicas y racistas (reales o imaginarias). Por lo general, estos problemas exceden el territorio deportivo (el estadio o la cancha) y esas disputas se trasladan a espacios contiguos (el pueblo, la ciudad), de allí su peligro social.

e) Las alteraciones sociales generadas por la práctica de las "apuestas deportivas", que estimulan la ludopatía y el arreglo de resultados en los encuentros deportivos.

f) Y, no menos importante que los casos anteriores, es el que se da mediante el estímulo del consumo de productos dañinos para la salud (refrescos de cola y comida chatarra), especialmente en niños y adolescentes, a través del uso de imágenes deportivas o de la figura de deportistas afamados en el ámbito nacional e internacional.

Con el fin de contribuir a este debate, a continuación presentaremos algunas de las ideas que cuestionan el carácter impoluto de los deportes modernos. La trascendencia de evidenciar estos enfoques críticos, radica en que ellos se gestaron en el mismo momento en que los deportes se expandían por el mundo como una novedad asociada al progreso y, en algunos casos, como un signo de civilidad.

\section{La crítica desde la gimnasia natural}

Uno de los primeros filósofos que escribió sobre los objetivos de los deportes y la gimnasia fue Herbert Spencer (1820-1903), quien desarrolló la teoría de la evolución como ley universal y base de una nueva filosofía, preocupándose de un modo especial por las funciones de los ejercicios físicos en el desarrollo de adolescentes y niños. Su interés por estudiar los fenómenos de la mente humana lo acercó a temas educativos. En 1860 publicó la obra Education, con el propósito de advertir, tanto a padres como maestros, respecto a la importancia de seguir un método "natural" como guía en todos los principios de la enseñanza humana. Este libro no sería aceptado por los críticos de la época, al juzgarlo escandaloso por defender el desarrollo natural de la inteligencia de los niños y proponer un sistema de enseñanza que se apoyaba en la libertad, en vez del orden y el castigo (Bohannan, 1997). Durante ese tiempo Spencer estaba en el apogeo de su carrera intelectual. Luego los juicios hacia la obra se tornarían favorables y sería reeditada en numerosas ocasiones, incluso traducido a, por lo menos, quince idiomas. De este modo sus ideas se incluyeron en programas de educación inicial en casi todo el mundo.

En el texto Education, Spencer (1904) trata de probar que la naturaleza posee un método 
de desarrollo intelectual, moral y físico y que el mismo tendría que servir de guía y norma para el despliegue de las acciones humanas, en especial, aquellas encaminadas a la educación de los niños. Además de constituir los cimientos de la educación formal. En este marco, Spencer sostenía que la educación del cuerpo cumplía con una labor significativa y que por su intermedio los adultos aprenderían cómo educar y criar a sus hijos y, entre otras lecciones: qué tipo de alimentos deberían suministrarles en los distintos periodos del año, cuánto debían descansar estos luego de las actividades diarias, cómo abrigarlos y el tipo de ejercicios que debían realizar.

Spencer, como filósofo, naturalista, psicólogo, pero, por sobre todo, como antropólogo, tenía una visión especial de la sociedad: la concebía como un organismo no diferenciado y simple, sobredimensionaba el carácter biológico de los seres humanos, considerándolos semejantes a los animales superiores, en particular, los mamíferos (Bohannan, 1997). De allí que para ilustrar sus ideas sobre la educación se soportó en ejemplos de la vida cotidiana de los campesinos. Este procedimiento, según sostiene, constituiría una herramienta pedagógica útil y adecuada para acercar conocimientos de índole científica a las personas poco ilustradas. De esta forma buscaba animarlas para que brindaran a sus hijos igual trato que a sus animales.

El autor reconocía cierta urgencia de trasladar los saberes obtenidos en los laboratorios al terreno de la educación doméstica y escolar ${ }^{6}$, dado que este tipo de instrucción terminaría por generar mejores ciudadanos ${ }^{7}$. Para Spencer los niños siempre obran por el impulso de sus instintos naturales. Ello ponía en evidencia otra de sus formulaciones: que los seres humanos estamos sometidos al mismo tipo de leyes orgánicas que los seres inferiores. De allí, la sugerencia a los educadores de poner en práctica esas leyes en la educación física de los niños y los jóvenes (Spencer, 1904). Si bien para mediados del siglo XIX muchas personas sabían del beneficio adquirido mediante las prácticas corporales,
Spencer opinaba lo contrario, de manera categórica y lapidaria sentenciaba que "la gimnasia constituía un mal necesario". Lo correcto, según su teoría, era seguir los movimientos "naturales" del cuerpo y no forzarlo a realizar acciones rígidas e involuntarias. Pues, según él:

Para los niños de uno y otro sexo, la actividad a que sus instintos los impele, es absolutamente esencial para su bienestar físico. Quienquiera que lo prohíba no hace más que oponerse a los medios naturales empleados para producir el mejor desarrollo físico (Spencer, 1904, p. 224).

La gimnasia, desde su particular punto de vista, era una actividad artificial que se tornaba negativa comparándola con los juegos libres de los niños. Declaraba que los movimientos realizados en la práctica de la gimnasia dirigida eran menos variados, produciendo una distribución de fuerzas desigual en el cuerpo, que representaría un factor fundamental para la generación de fatiga y cansancio. Además, para el autor, estos movimientos eran monótonos y de menor calidad que los obtenidos en las actividades lúdicas. Durante sus largas observaciones escolares, Spencer comprobó que el vivo interés y la alegría que los niños experimentaban en sus pasatiempos eran tan valiosos como el ejercicio corporal que los acompañaba; y por esto la gimnástica (no ofreciendo esos estímulos mentales) resulta ser fundamentalmente "defectuosa". Pero, a falta de algo mejor, el sistema de actividad ficticia de la gimnástica seguiría siendo útil para los niños (Spencer, 1904, pp. 222-224).

Según la visión de Spencer, el único rasgo positivo de las actividades gimnásticas se vinculaba con el sentido agonal, con el carácter competitivo presente en los torneos, con el sentido de lucha y sacrificio que los juegos transmitían al espíritu de los niños, que de alguna manera emulaba las acciones de la vida que en el futuro estos deberían enfrentar. En cierto modo, el pensador británico estaba adelantando las bases teóricas de lo que, cincuenta años después, conoceríamos por la obra de Ling, como estilo de "gimnasia na- 
tural o gimnasia sueca", una modalidad que tuvo enorme influencia entre los pedagogos mexicanos de principio del siglo XX.

\section{Los juegos como supervivencias culturales en la historia}

Años después, en el manual publicado en 1881 titulado Anthropology, uno de los padres fundadores de la antropología, Edward B. Tylor (1832-1917), incluiría un apartado especial sobre las prácticas lúdicas y las actividades físicas de las sociedades primitivas. En este trabajo, el autor difundiría los logros alcanzados por la ciencia del hombre. Entre los diversos temas que se tratan sobresalen los de lenguaje, escritura, ciencia, del mundo espiritual, historia, mitología, sociedad, artes útiles y artes recreativas; es decir, todo lo que se entendía formaba parte de la cultura material y espiritual de una sociedad.

Esta manera de investigar la totalidad de una sociedad, respondía a una modalidad propia de los evolucionistas decimonónicos de realizar "estudios que abarquen la totalidad de la cultura humana en el tiempo y el espacio" (Magrassi, 1986). Tal procedimiento estaba en consonancia con la idea desarrollada por Tylor respecto a su concepción de la cultura como "aquel complejo total que incluye conocimiento, creencia, arte, moral, ley, costumbre y otras aptitudes y hábitos adquiridos por el hombre como miembro de una sociedad" (Bohannan, 1997). Una definición trascendente que ejerció un papel relevante en el avance de las ciencias sociales y humanas, en particular, de las ciencias antropológicas.

En la obra citada, en dos capítulos diferentes, Tylor estudió el ámbito de las artes de los "pueblos primitivos". A las primeras denominó como "artes útiles", y comprendían todas aquellas actividades, técnicas, instrumentos y utensilios propios de las labores de defensa y subsistencia. El amplio conjunto de objetos incluía los que se manejaban para carpintería, transporte, agricultura, construcción, alimentación, abrigo, comercio y aseo personal (Tylor, 1973). A las segundas, las llamó "artes recreativas", dejando entrever que estas no conformaban el campo de los bienes materiales esenciales para la vida del hombre.

En la división propuesta por el autor, se anticipó una idea que luego florecería entre los tecnócratas, la cual percibe a las actividades artísticas como acciones del espíritu y complementarias de la industria y el mundo productivo. Este acervo de artes cubría todas las actividades inherentes al entretenimiento y solaz de los individuos y los colectivos: versos, música, baile, drama, escultura, pintura y juegos de todo tipo (Tylor, 1973). Para el autor, los juegos representaban artes recreativas, es decir, manifestaciones que tienen un fin en sí mismo, y que según sus propias palabras "consiste en hacer por hacer, esto es, en hacer sin propósito alguno" (Tylor, 1973, p. 353) ${ }^{8}$. Según Eric Dunning (1979) esta forma de conceptualizar a los juegos como actividades aisladas, desligadas de su entorno y sin fines prácticos visibles o latentes, se aceptaría y repetiría por diversos escritores, perdurando hasta nuestros días.

Los juegos, tal como los entendía Tylor, son "sobrevivencias" del pasado; es decir, instrumentos o prácticas de formas toscas y primitivas en desuso. Esta idea seguía la dirección reconocida por muchos evolucionistas de la época, para quienes las supervivencias cobraban valor al transformarse en indicadores del pasado que develaban el "desarrollo" alcanzado por los pueblos estudiados. Las matracas, por ejemplo, que eran empleadas en la antigüedad por las "tribus salvajes" para realizar diversos ceremoniales de gran seriedad -tanto en los tiempos de paz como en los de guerrase utilizaban en las sociedades modernas como juguetes para el entretenimiento de los niños. Lo mismo sucedía con el arco y la flecha, y con todos aquellos objetos que antaño eran herramientas o instrumentos esenciales para las tareas de defensa y subsistencia, y que en nuestros días forman parte del acervo lúdico de juguetes de entretenimiento entre los niños (Tylor, 1973). 
A su vez, Tylor suponía que algunos juegos podían considerarse como indicadores del progreso alcanzado por alguna sociedad. En este sentido, los entretenimientos no eran vistos como "reliquias degradadas del pasado", sino como adquisiciones en constante cambio (evoluciones), producto del proceso de desarrollo de la humanidad. Como ejemplo, Tylor expone el caso de los bailes públicos, que en los tiempos modernos se utilizan como un entretenimiento, pero que en el pasado sirvieron para la expresión de pasiones y grandes solemnidades. Lo mismo habría ocurrido con el teatro, que fue perdiendo su sentido religioso original para convertirse en un espectáculo complejo (Tylor, 1973). Esta idea sobrevive en quienes perciben a los deportes modernos (sports) como formas "evolucionadas" de otras primitivas?.

Tylor encontró un tercer tipo de juegos que, a diferencia de los anteriores, había pasado indemne por la historia, sin modificaciones, y luego otros que habrían experimentado una gran transformación para pasar a formas más elevadas, tal como el juego de pelota, ajedrez, tate-ti, dados y numerosos juegos de naipes (Tylor, 1973). A pesar de la importancia que podamos observar en las formulaciones realizadas por el autor, estas fueron ignoradas por los científicos sociales y no experimentarían continuidad. Incluso su definición de "juego" fue redescubierta cincuenta años después por Johan Huizinga, sin que se recuerde su autoría inicial.

\section{Los deportes, práctica arcaica de la clase ociosa}

Thorstein Veblen (1857-1929) fue un economista singular y uno de los académicos más controvertidos en la historia de los Estados Unidos. En 1899 escribió Teoría de la clase ociosa, donde retrata el esnobismo y la presunción social de ciertos sectores de la sociedad norteamericana de fines del siglo XIX y donde analiza el lugar que las prácticas deportivas tenían entre las clases altas de dicha sociedad (Galbraith, 2005). Una particularidad en la obra de Veblen es que no se interesó por investigar pobres o desposeídos, abundantes en esos tiempos, tampoco "indios" o "salvajes", que comenzaban a extinguirse. Por el contrario, y a diferencia de los antropólogos del XIX que realizaban sus estudios en lugares apartados del planeta, ello con el fin de investigar a los "otros", Veblen convirtió en objeto de estudio a la clase acaudalada, a la élite de su tiempo. Su obra Teoría de la clase ociosa fue escrita con un profundo sentido crítico y una alta cuota de ironía ${ }^{10}$, en el marco de una comunidad universitaria que condenaba a quienes se atrevieran a desafiar a la plutocracia de entonces ${ }^{11}$.

El objetivo del libro, según sus propias palabras fue "estudiar el lugar y valor de la clase ociosa como factor económico en la vida moderna" (Veblen, 2005). Su teoría sostenía que los integrantes de las clases altas en el transcurso de la historia siempre habían ocupado los lugares privilegiados en la escala social, siendo los encargados de las labores más cultas y heroicas, como la de ejercer el gobierno, la religión y la guerra. Las clases bajas, por su parte, habrían sido quienes oficiaran las tareas más duras y menos gratificantes, como las relacionadas con la industria y las tareas manuales de cobijo y subsistencia. Según este planteamiento, las clases altas se ocuparían de las labores dignas, de las que acarreaban hazañas y estaban impregnadas de proeza y que Veblen sentenciaba como actividades ociosas y depredadoras. Las clases bajas, por su lado, solo se dedicarían a las tareas indignas, degradantes, innobles, es decir, al trabajo (y preferentemente el trabajo físico). Para Veblen, este reparto de tareas y la diferencia social manifiesta contenían una situación excepcional: "la exención a las tareas industriales de las clases altas era, al mismo tiempo, la expresión económica de su superioridad de rango" (Veblen, 2005, p. 9). Esta condición de los ricos de no realizar tareas manuales estaba guiada por las leyes del "consumo ostensible", donde "el hecho de consumir bienes improductivos constituiría un signo de honor" $(p, 9)$. Lo que se manifestaba tanto en la clase de bienes 
consumidos como en las actividades realizadas durante los momentos de ocio.

Los vestidos de moda (faltos de toda funcionalidad) y los deportes (sin fines productivos o industriales) serían para Veblen, los mejores ejemplos de este tipo ${ }^{12}$. En este sentido, la institucionalización de la clase ociosa sería el producto del desarrollo evolutivo. Para demostrarlo recurriría al esquema que presentó Lewis Henry Morgan en la obra Ancient society (1877) de las tres etapas de la evolución social: salvajismo, barbarie y civilización (Bohannan, 1997). Tomando este esquema como referencia, el autor elaboraría los argumentos centrales de su teoría, encontrando que durante la época salvaje, las sociedades primitivas gozaban de una igualdad generalizada entre todos los miembros, sin distinciones ni posibilidades de implantación de una clase acomodada. Mientras que en la barbarie se comenzarían a producir numerosas diferencias en las tareas al interior de las sociedades: los hombres se dedicarían a la caza y la defensa y las mujeres a las labores industriosas. De esta manera, la clase ociosa comenzaría a emerger, para lo cual necesitaría, además, de dos condiciones indispensables: a) que la comunidad posea hábitos depredadores, y b) que cuente con los medios suficientes para generar un excedente que permita mantener a los que no trabajan. Así Veblen descubre cómo desde entonces este grupo de "privilegiados" se habría caracterizado por profusos atributos como son: la capacidad de demostrar poder, sea por la fuerza o por la riqueza; por la repugnancia al trabajo; la propensión a dominar; los buenos modales; la posesión de sirvientes como indicador de riqueza; el estatus que generan las actividades no productivas; el consumo ostensible de bienes improductivos y, como rasgo de honor, la demostración fastuosa de la riqueza, entre otras distinciones (Veblen, 2005).

En la sociedad moderna estos rasgos antiguos sobrevivirían en las manifestaciones del temperamento, mediante las cuales se pretendería obtener algún tipo de reputación catalogada como hazaña. Hazañas que serían señaladas por Veblen (2005) como "expresiones simples e irreflexivas de una actitud de ferocidad emulativa". Las guerras, los duelos entre caballeros y, en especial los deportes, constituyeron espacios predilectos donde poner a prueba estas actitudes. Así aconteció con todos los deportes jugados en esos tiempos: boxeo, atletismo, navegación deportiva, juegos de habilidad y destreza, entre otros. Según esta teoría, la afición a los deportes indicaría un desarrollo atrasado de la naturaleza moral del hombre, puesto en evidencia por el elemento de ficción que caracteriza estas actividades y que se reforzaría por las vicisitudes que sobrellevan las competencias (Veblen, 2005).

Para Veblen la transformación de los deportes como un medio de recreo sucedió porque estos se ajustaron al canon de "derroche ostensible de la clase ociosa", dado que poseen una finalidad objetiva inútil. De modo que los rasgos del hombre depredador no estarían ausentes en la sociedad moderna, solo dormitan en su subconsciente. Para que salgan a la luz haría falta un estímulo mayor que lo que brinda la cotidianidad, siendo las prácticas deportivas ejercicios adecuados para develar y poner en evidencia este tipo de arcaísmo (Veblen, 2005).

\section{Gráfica 2}

El poder destructivo de los deportes

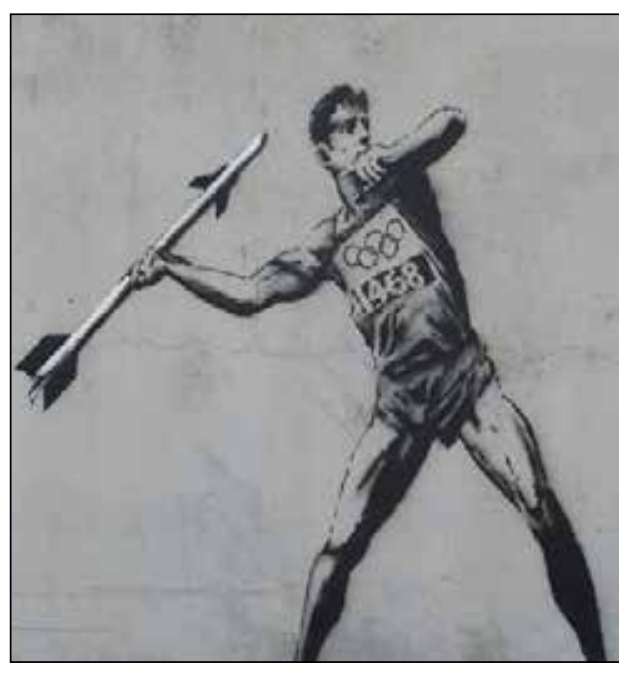

Fuente: Banksy (2012, citado por Horlock, 24 de julio de 2012) $)^{13}$. 


\section{Comentarios finales}

Como observamos, algunas de las impresiones sobre los deportes de ciertos intelectuales de fines del siglo XIX fueron de corte negativo. Sin embargo, el pesimismo manifiesto no llegó a interferir en la difusión y, mucho menos, en el desarrollo de los deportes. Por el contrario, en el transcurso del siglo XX los deportes acrecentarían su importancia social, alcanzando grados excelsos de perfeccionamiento y divulgación.

En los años sesenta de la centuria pasada, una corriente retomaría algunos de los planteamientos anteriores y elaboraría una teoría crítica del campo deportivo. Los autores alineados a esta corriente (neomarxista) construyeron sus argumentos basándose en el materialismo histórico, considerando que las condiciones de vida material de la sociedad (la infraestructura) son las que, en última instancia, determinan en cada periodo histórico la fisonomía de la sociedad, sus ideas e instituciones (la superestructura) (Harnecker, 1978). Los deportes modernos, vistos desde esta perspectiva teórica, se concibieron como producto del capitalismo liberal, de la sociedad burguesa (Guttman, 2004). Algunos estudiosos que representan esta línea crítica del pensamiento deportivo son Jean-Marie Brohm (1982), P. Laguillaumie (1972), George Vinnai (1986) y Luigi Volpicelli (1962). El deportista, según Berthaud (1972), se concibe como un instrumento, "un hombre-máquina en miniatura", integrado a otros objetos con la función de un único principio de organización: el rendimiento colectivo en el seno del universo temporal-espacial abstracto.

En este espacio el individuo está sujeto a imperativos técnicos que ocultan las estructuras de dominación autoritarias. La lógica de este sistema es represiva, y si el individuo la acepta pasivamente no quiere decir que no exista esta condición de sujeción, sino que "la represión está tan interiorizada y asimilada por el individuo que se confunde con su propia voluntad. $\mathrm{La}$ represión externa se convierte en autorrepresión" (Berthaud, 1972, p. 104).
Pero las razones precedentes, y su sentido crítico, no deben conducirnos a suponer que todas las observaciones realizadas sean erróneas. La comercialización de los atletas, la transformación de los clubes en empresas o sociedades anónimas, la fascinación por el récord, los daños físicos $y$, entre otros, la industrialización de los productos deportivos, son algunos de los asuntos que deben analizarse a cabalidad. Al mismo tiempo, estos problemas merecen la atención y estudio por parte de los investigadores, ya que solo de este modo las ciencias sociales lograrán contribuir al desarrollo de prácticas físicas saludables.

\section{Notas}

${ }^{1}$ Las Sátiras eran un tipo de "poemas maliciosos" que buscaban develar los vicios de los hombres (Guillén, 1991).

${ }^{2}$ Grafiti en las calles de Londres en 2012, en que se muestra un saltador de pértiga pasando por sobre una cerca con un colchón sucio (Going for molde).

${ }^{3}$ Futterman y Myerburg (1998) definen "muerte súbita" como la ocurrida de manera no violenta, ni traumática, que se produce de forma instantánea o después de haber realizado una actividad física deportiva. Este tipo de fallecimiento es infrecuente en personas menores de cuarenta años, y se presenta en aquellos sujetos que tienen problemas cardiovasculares.

${ }^{4}$ Ver el caso seguido por la justicia italiana respecto a la muerte de 45 futbolistas, todos ellos menores de cincuenta años, en el lapso de diez años en la ciudad de Turín. Diario El País, España, 8 de diciembre de 1988.

${ }^{5}$ Mónica de la Fuente del Rey (2009) señala algo relevante: "el sedentarismo es malo, pero el sobreentrenamiento es peor". La autora demuestra que los deportistas de alto rendimiento son más propensos a enfermedades infecciosas que aquellos que realizan una práctica moderada. Esto sucede -dice- debido "a 
que el ejercicio intenso disminuye la capacidad funcional de las células de nuestro organismo, mientras que el ejercicio moderado la aumenta" (De la Fuente, 2009, p. 105).

${ }^{6}$ De la Fuente (2009) decía: "Ya es tiempo, de que los beneficios obtenidos desde hace años por las reses vacunas y lanares, a consecuencia de las investigaciones de laboratorio, alcancen a nuestros niños" (p. 105).

7 "La primera condición para el bien del individuo en la vida es la de ser buen animal; y el que la población se componga de esos buenos animales, es la primera condición para la prosperidad nacional" (Spencer, 1904, p. 191).

${ }^{8}$ Esta definición resulta trascendente si consideramos que se anticipa en más de medio siglo a la que dio Huizinga (1996) en Homo ludens, quien entendía a los juegos como una actividad motivada por un "impulso primario", el cual subyace en toda acción humana. El juego, dice el autor, impregna y se encuentra presente en todos los órdenes de la vida de las personas, tanto la individual como la colectiva. Tal situación tiene como antecedente la premisa -que sostuvo y formuló el propio Huizinga- de que el juego "es anterior a la cultura". Desde esta perspectiva, lo "lúdico" estaría presente en la cultura como una acción congénita, como "Una actividad libre, fuera de la vida corriente, que se realiza sin ningún interés material, que se ejecuta dentro de un espacio y un tiempo, que está sometida a reglas y que da origen a asociaciones. El juego, así, representa una actividad que tiene un fin en sí misma" (p. 26).

${ }^{9}$ Idea que, como anticipamos, es defendida por numerosos historiadores de los deportes.

10 "El rico norteamericano nunca comprendió bien qué trataba de hacer Veblen o qué estaba haciendo con él. La pretensión científica, la ironía y las explicaciones minuciosas de que las palabras más peyorativas estaban siendo utilizadas en un sentido estrictamente no peyora- tivo lo pusieron más allá de la comprensión de aquel" (Galbraith, 2005, p. XXVI).

${ }^{11}$ Tal como ocurriera en 1895 con el profesor de economía Edward Benis, despedido de la Universidad de Chicago, al parecer, por criticar el monopolio del transporte en la ciudad (Veblen, 2005).

${ }^{12}$ Sobre el tema de la vestimenta y la moda, dedica el capítulo: "El vestido como expresión de la cultura pecuniaria" (Veblen, 2005).

${ }^{13}$ Grafiti en las calles de Londres en 2012 , simula a un lanzador de jabalina olímpico, a punto de proyectar un misil (Hackney celebra los Juegos Olímpicos).

\section{Referencias}

Berthaud, G. (1972) "Educación deportiva y deporte educativo". En: Partisans. ParisLibrairie Francois Maspero. (pp. 97-130).

Betancour, M., \& Almeida, A. (2001). Pierre de Coubertin y el mensaje educativo del olimpismo moderno. Vegueta, 6, 81-96.

Bohannan, P. (1997). Antropología. Madrid: Mc Graw Hill.

Brohm, J. M. (1982). Sociología política del deporte. México: Fondo de Cultura Económica.

Brohm, J. M. (2006). La tyrannie sportive: théorie critique d'un opium du peuple. París: Beauchesne éditeur.

Cabrera, J. (2004). Estampas de la Antigüedad Clásica. San José de Costa Rica: Editorial de la Universidad de Costa Rica.

Dunning, E. (1979) Dilemas de los planteamientos teóricos en la sociología del deporte. En G. Lüschen \& K. Weis (Comps.), Sociología del deporte (pp. 21-33). Valladolid: Editorial Minon. 
Dunning, E., \& Norbert, E. (1986). Deporte y ocio en el proceso de civilización. México: Fondo de Cultura Económica.

El fiscal de Turín investiga la muerte prematura de 45 futbolistas en Italia en los últimos 10 años. (08 de diciembre de 1988). El País. Recuperado de http://elpais.com/diario/1998/12/08/ deportes/913071607_850215.html.

Elías Norbert. (1986) "La génesis del deporte como problema sociológico". En: Dunning, E., \& Norbert, E. (1986). Deporte y ocio en el proceso de civilización. México: Fondo de Cultura Económica. (pp. 157-184).

Fábregas-Piug, A. (2001). El fútbol como escenario político. Diario de Campo, 14. México: CONACULTA-INAH.

Fuente De la, M. (2009). ¿Hasta dónde el deporte es saludale?. En A. Martínez, L. Gil, P. Serrano \& J. Ramos (Coords.), Nuevas miradas sobre el envejecimiento (pp. 91118). Madrid: Ministerio de Salud y Política Social; Instituto de Mayores y Servicios Sociales -[IMSERSO].

Futterman, L., \& Myerburg, R. (1998) Sudden death in athletes: An update. Sport Med, 26(5), 335-350. Recuperado de http:// www.uni.edu/dolgener/cardiovascular_phys/Electronic\%20Articles/Suddej_ Death_in_Athletes.pdf

Galbraith, J. K. (2005). Thorstein Veblen y la Teoría de la clase ociosa. En Veblen, $L a$ teoría de la clase ociosa (pp. 7-36). México: Fondo de Cultura Económica.

Gallo, L. E. (2006). El pensamiento educativo de John Locke y la atención a la Educación Física, Educación Física y deporte, 25(1), 97-114.

García-Ferrando, M. (1990). Aspectos sociales del deporte. Una reflexión sociológica. Madrid: Alianza.
Guillén, J. (1991). La sátira latina. Madrid: Akal.

Guttmann, A. (2004). From ritual to record. Nueva York: Columbia University Press.

Harnecker, M. (1978). Los conceptos elementales del materialismo histórico. México: Siglo XXI.

Horlock, A. (24 de julio de 2012). Banksy gets into the Olympic spirit by painting mural of javelin thrower armed with missile. Daily Mail. Recuperado de http://www. dailymail.co.uk/news/article-2178237/ Banksy-gets-Olympic-spirit-painting-mural-javelin-thrower-armed-missile.html

Huizinga, J. (1996). Homo Ludens. Buenos Aires: Emecé.

Laguillaumie, P. (1972). Para una crítica fundamental del deporte. En Partisans: Deporte, cultura y represión (pp. 32-59). París: Librairie Francois Maspero.

Locke, J. (1986). Pensamientos sobre la educación. Madrid: Ediciones Akal.

Lüschen, G., \& Weis, K. (Comps.) (1979). Deporte en la sociedad. Posición y cometidos de una sociología del deporte. En Sociología del deporte (pp. 9-19). Valladolid: Editorial Miñon.

Magrassi, G. E. (1986). Cultura y civilización desde sudamérica. Buenos Aires: Ediciones Búsqueda.

Mayer, F. (1984), Pedagogía comparada. México: Editorial Pax México.

Oliven, R., \& Damo, A. (2001). Fútbol y cultura. Buenos Aires: Enciclopedia latinoamericana de sociocultura y comunicación; Norma.

Sassano, M. (2003). Cuerpo, tiempo y espacio: principios básicos de la psicomotricidad. Buenos Aires: Editorial Stadium. 
Skirius, J. (1984). Vasconcelos: el político y el educador. En Á. Matute \& M. Donís (Comps.), José Vasconcelos de su vida y su obra (pp. 50-79). México: UNAM.

Spencer, H. (1904). La educación: intelectual, moral y fisica. Nueva York: D. Apletton y Compañía.

Thomas, R., Haumont, A., \& Levet, J. (1988). Sociología del deporte. Barcelona: Ediciones Bellaterra.
Tylor, E. B. (1973). Antropología. Madrid: Editorial Ayuso.

Veblen, T. (2005). Teoría de la clase ociosa. México: Fondo de Cultura Económica.

Vinnai, G. (1986). El fútbol como ideología. México: Siglo XXI.

Volpicelli, L. (1962). Industrialismo y deporte. Buenos Aires: Paidós. 